\title{
Factors Influencing Consumers' Purchasing Behavior on Organic Vegetables: A Case Study in Vientiane, Lao PDR
}

\author{
Chaitor Poyearleng, Zhao Kai*, Saleh Shahriar, Ouaimon Payang Slim Reakine \\ College of Economics and Management, Northwest A\&F University, Yangling, China \\ Email: chaitorpyl@nwafu.edu.cn, `zhaokai@nwafu.edu.cn, shahriar@nwafu.edu.cn, slimounaimon@yahoo.fr
}

How to cite this paper: Poyearleng, C., Kai, Z., Shahriar, S. and Reakine, O.P.S. (2019) Factors Influencing Consumers' Purchasing Behavior on Organic Vegetables: A Case Study in Vientiane, Lao PDR. Open Journal of Social Sciences, 7, 199-215.

https://doi.org/10.4236/jss.2019.72017

Received: January 4, 2019

Accepted: February 18, 2019

Published: February 21, 2019

Copyright (๑ 2019 by author(s) and Scientific Research Publishing Inc. This work is licensed under the Creative Commons Attribution International License (CC BY 4.0).

http://creativecommons.org/licenses/by/4.0/

\section{(c) (i) Open Access}

\begin{abstract}
This article aims to study the factors influencing consumers' purchasing behavior on organic vegetable. The main instrument for data collection used in this study is the questionnaire distributed to 323 respondents on the basis of random and convenience sampling. The purpose of this study is to examine the reliability of the empirical data; therefore, the consistency analysis has been done using Cornbrash's alpha method. Various statistical methods and techniques such as factor analysis and multiple linear regression models were run by means of the data collected through a structured questionnaire. In terms of proportional marketing mix impact, it is observed that place, product and promotion factors have higher impacts on organic vegetable consumers decision process; whereas, the factor with medium level is price. Results showed the strong support for consumers' attitude towards organic vegetables is influenced by product specific attitude, health consciousness, perceived price and knowledge of organic vegetables.
\end{abstract}

\section{Keywords}

Influencing Factors of Consumer Behaviors, Consumers' Purchasing

Behavior, Organic Vegetable, Vientiane Capital of Lao, Lao PDR

\section{Introduction}

Organic food is considered more environment-friendly when compared to conventional food. Organic farming includes a wide range of practices that are expected to be "socially, ecologically, and economically sustainable" [1]. Organic farming practices produce food that provides health benefits such as higher levels of nutrient content [2]. Organic food consumption has increased the ${ }^{\star}$ Corresponding author. 
five-fold in the last six years. The growth of organic product is seen as part of emerging marketing trends where consumers seek to know what an organic product can deliver before making purchase decisions [3]. Therefore, investigating drivers for organic food consumption has become an important marketing research issue in recent years [4]. A very large number of consumers from all over the world are concerned with environmental problems [5]. In order to understand why customers are interested in purchasing a product, it is necessary to understand the nature of the finalized buying decisional process and, therefore, of what they want or try to achieve through the purchase [6]. From a cognitive perspective, consumer behavior can be defined as "the activities that people engage in when selecting, purchasing, and using products and services to satisfy needs and desires" [7]. The alternative food systems discourse has increasingly been concerned with natural products and social responsibility [8]. This is because current environmental dreadful conditions are ever more menacing the consumer health and well-being [9]. The domestic organic market in Lao appears to be growing rapidly. Since December 2006 when the first organic farmers' market was organized by PROFIL at That Louang in Vientiane city, the market has expanded significantly both in terms of the number of farmers participating, the range of products, market frequency, and sales volume. At the beginning, the market was organized once a month and later on became a weekly event [10]. Some studies provide an overview of the most important strengths, weaknesses, opportunities and threats (SWOT analysis) of the Lao vegetable sector, with regard to the launching an organic vegetable project oriented towards exports and local trade [11]. Currently, Lao has no national regulations on its organic agriculture and trade. The producers and traders can voluntarily choose whether to have organic certification and which organic standards to apply [10]. This limited marketing system has effectively introduced organic products in Lao, and can serve as a basis for further expansion. But it is highly dependent on outside support and may not be sustainable over the long-term [11].

Despite the growth in organic food agriculture and a large number of studies investigating factors driving consumer purchasing intention of organic food, the organic food market share and consumer expenditure share of organic food and beverages are relatively low [12]. Various psychological/behavior theories have been applied to incorporate more dimension to investigate factors that form the intention and drive behavior to purchase organic food. There are some studies with regard to the consumption of some products, such as, animal meats [13]-[17], honey [18] [19], water [20], and the garments industry [21] [22]. However, there is a dearth of literature on the organic vegetables in Lao PDR. We have, therefore, undertaken this project to fill the existing research gap. This paper aims to study the factors influencing on consumers' purchasing behavior on organic vegetables. The primary aims are to develop a better understanding of the marketing mix output in important organic vegetable, which can be used as guidelines to increase output. This is the first empirical work on consumption 
in Lao with regard to the organic vegetables. It is very important for marketers to be aware that the change in consumer's behavior towards organic vegetables may help both consumers of organic interest and marketers to drive growth in the organic vegetable market. These will be critical issues as long as organic vegetable remains one of the main commercial crops of Lao.

The remainder of the paper is organized into several segments. Section 2 presents the theoretical analysis and research hypotheses. Section 3 details the data sources and research methods. The next Section 4 is the presentation of the results. Finally, along with discussion, some concluding observations are made in Section 5.

\section{Theoretical Analysis and Research Hypothesis}

\subsection{Theoretical Framework}

The four traditional Ps of the marketing mix, product, price, promotion and place, and how they will need to change to facilitate greater sustainability outcomes, is introduced by [23]. Marketing approach based on social, environmental and economic welfare [24]. These tenets are often referred to as the 4Ps of marketing - product, price, place and promotion [25]. In the proposed marketing mix for organic vegetable to the traditional four Ps are added a slightly recalibrated consumer, health consciousness and knowledge of organic vegetables, and, in addition, attitude, behavior and purchase [26].

\subsubsection{Product}

Understanding individuals attitudes better can aid marketers, policy makers, and even producers to promote ethical consumer habits and encourage them to use or consume products that are environmentally-friendly [27]. Attitude plays a strong role in influencing the behavior and is necessary to consumer behavior research [28]. Organic vegetable production does not use synthetic pesticides and seeks to produce vegetables in a natural way [29]. A product that has negative environmental consequences can be severely disadvantaged as consumers consider the impact of that product upon the environment Low commitment of private actors in implementing state strategies, and unwillingness of state authorities for transparency, information disclosure and being held accountable [30]. Ideally, the repeated purchase of sustainable products will lead to sustainable habits [31]. Knowing which markets to target, and when and how to target them, will optimize production and profits in the organic foods segment [25]. The construct of product-specific attitude would be more appropriate in order to empirically investigate factors influencing individual's consumption of organic food as they are deemed highly involved with the product and express their actual attitude on the product towards consumption and not the perception that could result in potential bias.

\subsubsection{Price}

Certified organic foods are generally more expensive than conventional prod- 
ucts/foods. Price becomes important in the organic food marketing. According to [32] Behavior intentions applied to price can include purchase intentions. They need to show that their business operations are in line with the rules and regulations of government environmental standards and other related bodies [33]. Price policy cannot be regarded separately, especially from product policy but from the full spectrum of the interdependent marketing measures as well [34]. Low prices resulted in significantly higher facial muscle activity related to positive emotions than did high prices [35]. [36] found that low prices increased contempt and shame, while they reduced distress and anger if high value was perceived. Increased prices of organic produce by taking into account social externalities may hinder low-income consumers from purchasing more socially responsibly produced organic products [37] and [38]. That is why, we aim to test the relationship between consumer perception of price and consumer attitude about organic foods.

\subsubsection{Promotion}

Promotion is the means by which firms attempt to inform, persuade, and remind consumers directly or indirectly about the products and brands that they sell [39]. [40] communicates with the consumer and others take holders about the company as a whole. Marketing communications also represent the brand's voice and allow it to build relationships with customers [39]. Marketing managers navigate the difficult waters of moving companies and brands towards more sustainable market offerings and the societal impacts of consumption of those offerings [26].

\subsubsection{Place}

Place is typically associated with distribution channels and facility location. Place refers to providing products for easy access and includes intensive, selective, or exclusive distribution and franchising [41]. Place, or marketing channels, is the range of "independent organizations involved in the process of making a product or service available for use or consumption" [39]. Green retailing and corresponding regional retail management [42]. China's green place research is centered on green logistics and the relationship between green logistics management and business performance [43].

\subsubsection{Knowledge of Organic Vegetables}

The study of consumer behavior is supported by the theory of planned behavior [44] [45] [46]. This theory explores motivational influences on behavior that is under the purview of an individual on his own will to provide a framework of consumer behavior. Purchase of environmental friendly product cannot be separated from knowledge of consumers about the environment and ecology [47]. Therefore, consumers' awareness and knowledge about organically produced food pay a significant role in making purchase related decisions [48]. Consumer purchase intention would be different if consumers have varying level of knowledge [49]. Consumers have a need to know what they purchase to satisfy their 
needs and wants. Food knowledge is an important factor that can affect consumer behavior in which knowledge is a cognitive learning [50]. A previous study found that consumers' knowledge of social and environmental issues positively affects their attitude and purchase behavior towards organic food products [51].

\subsubsection{Health Consciousness}

Previous findings show that health benefit is one of the prime reasons to the consumers for purchasing of organic vegetables [52]. Found that health has a significant influence on consumer attitudes. Organic products are free from pesticides and chemical fertilizers, and are pure, natural and healthy [51]. Health variables have a positive effect on consumer attitude towards organic foods in Malaysia [53]. Previous findings show that health benefit is one of the prime reasons to the consumers for purchasing of organic foods. Health factors are the most significant variables affecting consumers' willingness to purchase organic foods [54].

\subsection{Hypothesis}

The products' quality cue that is the price appropriate to the distribution channel, product-specific attitude and the moderating role of marketing promotion are investigated in this study to explain the variance in organic vegetables consumption behavior. The rationales for investigating the factors are discussed in the literature review. The following hypotheses will be examined:

H1. Perceived price influences the consumer attitude towards organic vegetable.

H2. Consumers' knowledge of organic vegetable has a positive influence on their attitude.

H3. Product-specific attitude positively influences consumption of organic vegetable.

H4. Health consciousness has a positive influence on the consumer attitude towards organic vegetable.

The remainder of this study is structured as literature pertaining to factor influencing organic vegetable consumption is reviewed. Thus, the conceptual model is show in Figure 1.

\section{Data and Research Methods}

\subsection{Data}

\subsubsection{Study Area}

A face-to-face survey was conducted in front of organic vegetable outlets and departmental stores having organic vegetable section at Thatlouang and Jao anouvong markets in Vientiane, Lao (see Figure 2). The random sampling method used approaching consumers who were coming out of the tow markets. The study areas were selected for a couple of reasons. First, the two markets were the first places for organic vegetables. Second, the consumers in the markets are 


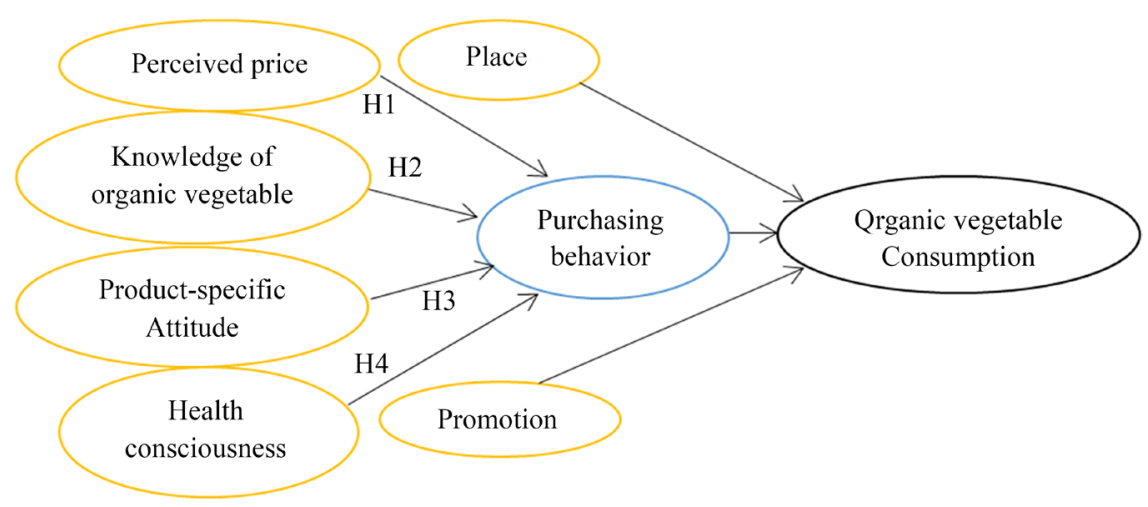

Figure 1. Conceptual model.
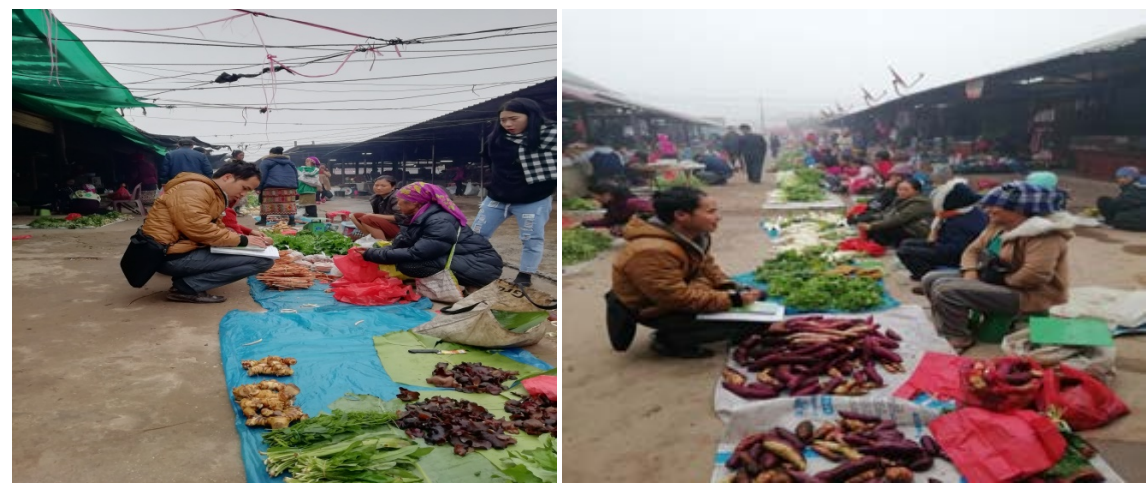

Figure 2. Field survey in Lao.

also increasing day by day because of the growing demand. Third, Vientiane capital is the most populous people from all parts of Lao come to Vientiane for education, employments.

\subsubsection{Data Sources}

To test the proposed hypotheses, the empirical data has been collected through a structured questionnaire. This study employed a quantitative research design, used a structured questionnaire developed in English and Laos. The questionnaire was composed of three sections with question statements adapted from previous studies. The first part comprised of questions pertaining to demographic characteristics (gender, education, monthly household income, family status, and family member). The second part of the questionnaire collected data on Consumers' behavior organic vegetable consumption. The third part of the questionnaire focused on ingredients marketing mix factors influencing respondents' organic vegetable consumption, including products, prices, distribution channels and marketing promotion, health consciousness, knowledge of organic vegetables and attitude. The items for all investigated variables were anchored on a 5-point Likert scale with 1 referring to strongly disagree and 5 referring to strongly agree. The questionnaire was subsequently piloted with 10 consumers of organic foods to ensure that the questions and response formats were clear. Minor amendments were made based on feedbacks received from the pilot study. 
This study used infinite population formulaically random sampling of $30 \%$ or 0.3 of the population, requiring a confidence level of $95 \%$ and accepting discrepancy by $5 \%$ or 0.05 , confidence level determined $Z_{0.05}=1.96$, questionnaires were distributed to only those respondents who were aware of organic vegetables. Thus, a total 323 questionnaires were distributed. Respondents were sampled from 150 with thatlouang market and 173 with Jao anouvong market during 1st - 30th September 2018 in Vientiane, Lao, and the participation of respondents in the study was on a voluntary basis. Therefore, we assume that our sample includes the organic vegetables consumers belonging to different regions of Lao, cultures and backgrounds.

\subsection{Research Methods}

The responses were thoroughly checked and coded for the purpose of statistical analysis. Comparison marketing mix ingredients influence the decision to purchase organic vegetables used T-test the sample group with variables two groups are independent of each other, and used F-test with the data of the sample with variables more than two groups which the One-way ANOVA in case of statistical significance (Sig), comparative analysis of each pair with values LSD with a confidence level of 95\%, The data was entered in Statistical Package for Social Sciences (SPSS) version 22. To examine the reliability of the empirical data, consistency analysis has been done using Cornbrash's alpha method. Various statistical methods and techniques such as factor analysis; multiple linear regression analysis was used to analyze quantitative data collected through a structured questionnaire.

\section{Results and Analysis}

\subsection{Descriptive Statistical Analysis}

Table 1 shows the profile of respondents the results show that $40.9 \%$ of respondents were male and $51.9 \%$ were female. Regarding educational level most of the respondents have a bachelor degree $51.7 \%$ and higher degree $21.7 \%$, while a smaller number had a secondary education $15.8 \%$ and $10.8 \%$ had attained higher bachelor's degree. As for employment most of the respondents have a job in the private $26.9 \%$ and Private business owner $22.3 \%$, while a smaller number were student $20.4 \%$, government staff $18.3 \%$ and $12.1 \%$ government enterprises. In terms of monthly income, most of the respondents earned $\$ 200$ - \$500 (52.9\%), while a smaller number earned less than $\$ 200$ (24.5\%) and more than $\$ 500$ (22.6\%). The family status of the respondents those $36.8 \%$ were single and $63.2 \%$ were married. As for the family member, most of the respondents had between 3 - 6 persons 58.5\%, while a smaller number had less than 3 persons $21.1 \%$ and more than 6 persons $22.6 \%$. The findings indicated that most of the respondents were married female, obtain Bachelor's degrees, have a job with private staff earned monthly income $\$ 200$ - $\$ 500$ and them family member were between 3 6 persons. 
Table 1. Profile of the respondents.

\begin{tabular}{cccc}
\hline \multirow{2}{*}{ Characteristics } & & $\begin{array}{c}\text { Frequency } \\
(\mathrm{N}=323)\end{array}$ & $\begin{array}{c}\text { Percentage } \\
(\%)\end{array}$ \\
\hline Gender & Male & 132 & 40.9 \\
Education Level & Female & 191 & 59.1 \\
& Secondary Education & 51 & 15.8 \\
& Higher degree & 70 & 21.7 \\
& Bachelor's degree & 167 & 51.7 \\
Employment & Higher Bachelor's degree & 35 & 10.8 \\
& Student & 66 & 20.4 \\
& Government staff & 59 & 18.3 \\
& Government Enterprises & 39 & 12.1 \\
& Private staff & 87 & 26.9 \\
Monthly income & Private business owner & 72 & 22.3 \\
& $<200 \$$ & 79 & 24.5 \\
& 200 - 5000 $\$$ & 171 & 52.9 \\
Family status & $>500 \$$ & 73 & 22.6 \\
& Single & 119 & 36.8 \\
Family members & Married & 204 & 63.2 \\
& $<3$ persons & 68 & 21.1 \\
& 3- 6 persons & 189 & 58.5 \\
& $>6$ persons & 66 & 20.4 \\
\hline
\end{tabular}

The consumers' purchasing behaviors on organic vegetable were analyzed and the summary is presented in Table 2, shows the results that $34.7 \%$ of respondents purchased organic vegetables at Thatluang market and $65.3 \%$ purchased at Jao anouvong market. Regarding the day purchasing most of the respondents purchased on weekends $71.8 \%$ and purchased on weekdays $28.2 \%$. The frequency purchased most of the respondents purchased twice per week 50.5\%, more than third per week $32.8 \%$ and once per week $16.7 \%$. Respondents marked the healthy contents as the main reason of their answers for the purchase of organic vegetable. However, the majority of respondents supported that benefits such as healthy content, personal preference, environment friendly and better taste are the reasons to choose the organic vegetables (see Figure 3). A total of $34.7 \%$ of the people agreed that healthy contents play an important role in making a purchasing decision. This confirms the response to the previous results where respondents marked healthy content as the single largest individual reason for the purchase of organic vegetables (34.7\%). In terms of quantities purchasing, most of the respondents purchased $5-10 \mathrm{~kg} 45.85 \%$, while a smaller number purchased more than $10 \mathrm{~kg} 28.2 \%$, purchased $2-5 \mathrm{~kg} 18.3 \%$ and less than $2 \mathrm{~kg} 7.7 \%$. As for the Purchasing spend, most of the respondents paid $\$ 20-\$ 50$ (37.2\%), paid $\$ 51$ - $\$ 100$ (32.8\%), while a smaller number paid more than $\$ 100(18.0 \%)$ and paid less than $\$ 20(12.1 \%)$. The consumers' purchasing behaviors on organic vegetable were analyzed and the summary is presented shows the results that most respondents purchased organic vegetables at Jao anouvong market, regarding the day on Sunday, the frequency purchased twice per week respondents marked healthy content as the main reason their answer for the purchase of organic vegetable. In terms of quantities purchased 5 - $10 \mathrm{~kg}$ as for the paid $\$ 20$ $\$ 50$. 
Table 2. Consumers' purchasing behavior on organic vegetable.

\begin{tabular}{cccc}
\hline variables & & Frequency $(\mathrm{N}=323)$ & Percentage (\%) \\
\hline \multirow{2}{*}{ Location purchasing } & Thatluang Market & 112 & 34.7 \\
& Jao Anouvong Market & 211 & 65.3 \\
Day purchasing & Weekdays & 91 & 28.2 \\
& Weekends & 232 & 71.8 \\
Frequency purchasing & 1 per week & 54 & 16.7 \\
& 2 per week & 163 & 50.5 \\
Reason purchasing & $\geq 3$ per week & 106 & 32.8 \\
& Healthy contents & 112 & 34.7 \\
& Better taste & 60 & 18.6 \\
Quantities purchasing & Environmental friendly & 72 & 22.3 \\
& Personal preference & 79 & 24.5 \\
& $<2 \mathrm{~kg}$ & 25 & 7.7 \\
& $2-5 \mathrm{~kg}$ & 59 & 18.3 \\
& $5-10 \mathrm{~kg}$ & 148 & 45.8 \\
Purchasing spend & $>10 \mathrm{~kg}$ & 91 & 28.2 \\
& $<\$ 20$ & 39 & 12.1 \\
& $\$ 20-\$ 50$ & 120 & 37.2 \\
& $\$ 51-\$ 100$ & 106 & 32.8 \\
& $>\$ 100$ & 58 & 18.0 \\
\hline
\end{tabular}

\section{Organic vegetable}

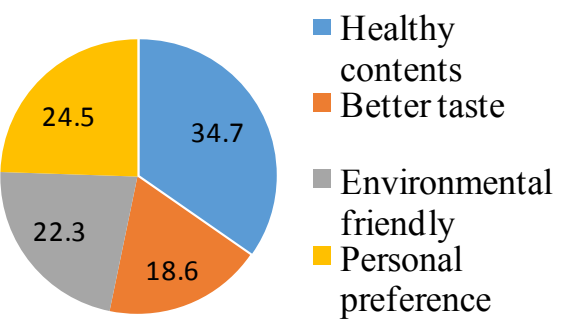

Figure 3. Reasons of organic vegetable purchasing.

\subsection{Empirical Results Analysis}

Table 3 presents the analytical results. It shows that product factors have an overall Mean $=3.46$, which was high level, considering each of the components in products, it is likely that consumers were most important convenient packaging looking clean with Mean $=3.64$ in high level and consumers the lowest important were confidence the vegetables have been identified chemical-free vegetables by FAO as Mean = 3.35 was medium level. As for price factor have an overall Mean $=3.38$ which was moderate, when considering each other of components in prices, consumers were most important on the price of organic vegetable was in accordance with benefits Mean $=3.53$ which lie at high level and the lowest average was price bargained had the Mean $=3.14$ was medium level. In terms the results of the place factors have an overall Mean $=3.47$, which results in high level, when we consider each of the elements consumers were important for public relations and there have signs of innocence to be the highest with Mean $=3.58$ was in high level, and there was an appointment market atmosphere with Mean $=3.30$ in the middle level. As for that promoting marketing 
Table 3. Marketing mix impact toward purchasing organic vegetable.

\begin{tabular}{ccccc}
\hline Marketing mix & Item & Mean & S.D & Decision \\
\hline \multirow{4}{*}{ Product Specific Attitude } & $P S A 1$ & 3.44 & 0.870 & High \\
& $P S A 2$ & 3.42 & 1.056 & High \\
& $P S A 3$ & 3.35 & 0.759 & Medium \\
& $P S A 4$ & 3.54 & 0.899 & High \\
& $P S A 5$ & 3.39 & 0.757 & Medium \\
& $P S A 6$ & 3.64 & 0.889 & High \\
Perceived Price & $P P 1$ & 3.32 & 1.018 & Medium \\
& $P P 2$ & 3.42 & 0.868 & High \\
& $P P 3$ & 3.14 & 1.029 & Medium \\
& $P P 4$ & 3.48 & 0.969 & High \\
& $P P 5$ & 3.53 & 0.940 & High \\
& P1 & 3.45 & 1.015 & High \\
Place & P2 & 3.47 & 1.093 & High \\
& P3 & 3.52 & 1.101 & High \\
& P4 & 3.44 & 1.152 & High \\
& P5 & 3.50 & 0.966 & High \\
& P6 & 3.30 & 1.106 & Medium \\
& P7 & 3.58 & 0.992 & High \\
& P8 & 3.54 & 1.151 & High \\
& PMT1 & 3.24 & 1.070 & Medium \\
& PMT2 & 3.43 & 0.934 & High \\
& PMT3 & 3.62 & 0.946 & High \\
\hline
\end{tabular}

Notes: $P S A$ Mean $=3.46, \mathrm{SD}=0.355 ; P P$ Mean $=3.38, \mathrm{SD}=0.407 ; \mathrm{P}$ Mean $=3.47, \mathrm{SD}=0.487$ and $\mathrm{PMT}$ Mean $=3.43, \mathrm{SD}=0.569$.

factors average Mean $=3.43$ which results in high level, considering the elements that consumers agree the seller has a good spirit on average Mean $=3.62$ at high level, followed by provides information and confirms from the seller is the organic vegetable with Mean $=3.43$ also in high level and discount of produce or free some produce in sometime with Mean $=3.24$ in the medium level. Marketing mix impact consumers toward purchasing organic vegetables found that the factors most respondents concern with the average in high level in place factor, product factor and promotion factor respectively the factor with medium level was price (see Figure 4).

Table 4 summarizes the results of the multiple linear regressions $M L R$ analysis was performed (hypotheses testing). The regression model predicts the influence of product specific attitude $P S A$, health consciousness $H C$, perceived price $P P$ and knowledge of organic vegetables $K O V$ on dependent variable consumer attitude $A T T$. Results of regression analysis revealed that these four factors (independent variables) account for $15.1 \%$ of explained variances for consumer attitude towards organic vegetables products; $\mathrm{R}^{2}=0.151$ and $F=14.173$. Results confirm that the hypotheses $\mathrm{H} 1$ to $\mathrm{H} 4$ are in expected direction $(\beta=$ $-0.119, \mathrm{p}=0.022 ; \beta=-0.127, \mathrm{p}=0.016 ; \beta=0.181, \mathrm{p}=0.001$ and $\beta=0.248, \mathrm{p}=$ $0.000)$ as it is statistically significant. Therefore, $\mathrm{H} 1, \mathrm{H} 2, \mathrm{H} 3$, and $\mathrm{H} 4$ were supported. According to results obtained, it can be said that consumer attitude towards organic vegetables is influenced by product specific attitude, health consciousness, perceived price and knowledge of organic vegetables. 
Table 4. Multiple regression analysis predicting attitude consumers' organic vegetable.

\begin{tabular}{ccccccccc}
\hline Predictors & Mean & SD & $\beta$ & \multicolumn{2}{c}{ Regression analysis } & \multicolumn{2}{c}{ Collinearity } \\
\hline & & & & SE & $\mathrm{t}$ & Sig & Tol & VIF \\
\hline$P S A$ & 3.46 & 0.355 & -0.119 & 0.068 & -2.297 & 0.022 & 0.998 & 1.002 \\
$H C$ & 3.47 & 0.463 & -0.127 & 0.053 & -2.420 & 0.016 & 0.976 & 1.025 \\
$P P$ & 3.38 & 0.407 & 0.181 & 0.061 & 3.418 & 0.001 & 0.947 & 1.055 \\
KOV & 3.46 & 0.457 & 0.248 & 0.055 & 4.631 & 0.000 & 0.928 & 1.077 \\
\hline
\end{tabular}

Notes: $\mathrm{R}^{2}=0.151, F=14.173, P S A$ Product Specific Attitude, $H C$ Health Consciousness, $P P$ Perceived Price, KOV Knowledge of Organic Vegetable.

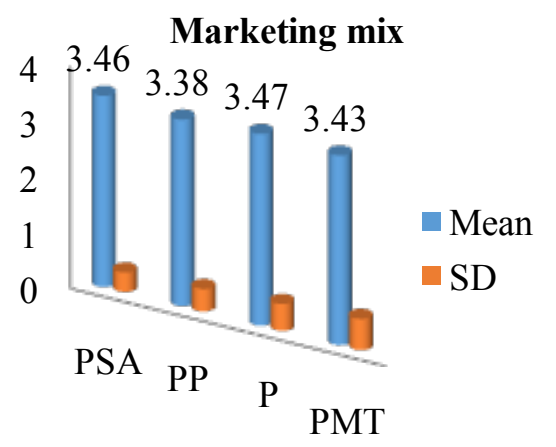

Figure 4. Decision of purchasing.

\section{Conclusion and Discussion}

\subsection{Conclusion}

The main objective of this study is to study the factors influencing consumers' purchasing behavior on organic vegetable products in Vientiane, Lao. The tool used in this study is the questionnaire distributed to 323 samples on the basic of random and convenience sampling. The collected data is then analyzed through descriptive statistics process including frequency, percentage, mean and standard deviation. To examine the reliability of the empirical data, consistency analysis has been done using Cornbrash's alpha method. Various statistical methods and techniques, such as the factor analysis, multiple linear regression analysis, were used to analyze quantitative data collected through a structured questionnaire.

First, the findings indicated that most of the respondents are married female, obtain Bachelor's degrees, have a job with private staff earned monthly income $\$ 200$ - $\$ 500$ and their family members are between 3 - 6 persons.

Second, the consumers' purchasing behaviors on organic vegetable were analyzed and the summary shows that most respondents purchased organic vegetables at Jaoanouvong market at the Weekends; the frequency purchased twice per week; respondents marked healthy content as the main reason for their answer for the purchase of organic vegetable. As for quantities purchased $5-10 \mathrm{~kg}$, they paid $\$ 20$ - $\$ 50$.

Third, in terms of proportional marketing mix impact consumers toward 
purchasing organic vegetables, we found that the concerning factors were high level in place factor, product factor and promotion factor and the factor with medium level was price. It can be said that consumers' attitude towards organic vegetables is influenced by product specific attitude, health consciousness, perceived price and knowledge of organic vegetables.

\subsection{Discussion}

Reflecting on the findings on varieties of vegetables used in food businesses, we propose focusing interventions on improving the chemical safety of tomatoes, cabbage and lettuce. Although systematically recorded disaggregate data are not available, tomato is visibly the vegetable used most in the three cities. Cabbage pests are difficult to control in the West African context [55]. Also, the importance of search attributes for food vendors buying vegetables shows that certified organic produce will need to provide the same search cues as conventional vegetables. Moreover, it will be necessary to take into account the complexity and cost of marketing a certified product in the food vending sector [56]. Recent studies acknowledged other self-interest motives such as self-representation or self-identity in consuming organic product [57] and [58]. Many of the consumer studies on organic food have considered factors that motivate consumers for organic food dues and consumer's profile who buy organic foods [59]. Foreign companies who intend to expand the market of their organic products in developing countries may also consider the findings of this research while drafting more effective strategies to better market and ensure more consumption of their product [60]. The discrete choice models provide some information to single out target groups for certified organic vegetables. Surprisingly, vendors in higher class categories associated lower utility with producing labeled organic [29]. Furthermore, "taste" is an important attribute in consumption [61] [62].

Important to recall that these findings are based on perceptions (purchase intention) and also indicated by convenient respondents who are not necessarily engaged in the act of consumption where they will help to provide a valid or unbias response, whereby this study is based on actual consumption and participated by only those who are actively consuming organic food providing more accurate and actual response on the motivation or driver [60]. The study focused on knowing the factors influencing organic food purchase intention with moderating role of awareness. Secondly, the results of Pakistan, Turkey and Iran were also compared. As in Pakistan the attitude and health consciousness found to be the better predictors of organic food purchase intention, and their interaction terms were also significant [63]. The study provides guidelines and suggestions for retailers who are selling organic foods. Besides this, the study can be helpful for the organic food manufacturers to identify their target consumers by showing the influence of socio-demographic factors on organic food purchases [48]. The study faces two limitations. First, its sample is limited to consumers who live in two major Vietnamese cities, which limits generalization to the over- 
all Vietnamese population. Second, all survey data collected in this study are self-reported and may thus suffer, to some extents, from recall or social desirability bias, which limits extrapolation of the study findings to actual behavior [64].

This research would be useful in policy decision-making process with regard to organic products. This work will provide insights in marketing practices and strategy formulations.

\section{Acknowledgements}

The authors would like to thank the Laos' respondents for their verbal consent to participate in this research project during the fieldwork in 2018. The first author would like to thank the China Scholarship Council (CSC) for hosting and supporting this research project.

\section{Author Contributions}

Chaitor Poyearleng (CP), Zhao Kai (ZK), Saleh Shahriar (SS) carried out the study from conceptualizing, planning and designing to writing. $\mathrm{CP}$ and Ouaimon Payang Slim Reakine (OP) collected the data. CP, ZK and SS selected the research methodology. ZK supervised and administered the project. CP, SS, and $\mathrm{OP}$ conducted the data analysis. $\mathrm{CP}$ wrote the original paper. The final version was reviewed and approved by all authors.

\section{Conflicts of Interest}

The authors have no conflicts of interest.

\section{References}

[1] Bourn, D. and Prescott, J. (2002) A Comparison of the Nutritional Value, Sensory Qualities, and Food Safety of Organically and Conventionally Produced Foods. Critical Reviews in Food Science and Nutrition, 42, 1-34. https://doi.org/10.1080/10408690290825439

[2] Crinnion, W.J. (2010) Organic Foods Contain Higher Levels of Certain Nutrients, Lower Levels of Pesticides, and May Provide Health Benefits for the Consumer. Alternative Medicine Review, 15, 4-13.

[3] Thøgersen, J., Zhou, Y. and Huang, G. (2016) How Stable Is the Value Basis for Organic Food Consumption in China? Journal of Cleaner Production, 134, 214-224. https://doi.org/10.1016/j.jclepro.2015.06.036

[4] Squires, L., Juric, B. and Cornwell, T. (2001) Level of Market Development and Intensity of Organic Food Consumption: Cross-Cultural Study of Danish and New Zealand Consumers. The Journal of Consumer Marketing, 18, 392-409. https://doi.org/10.1108/07363760110398754

[5] Diekmann, A. and Franzen, A. (1999) The Wealth of Nations and Environmental Concern. Environment and Behavior, 31, 540-549. https://doi.org/10.1177/00139169921972227

[6] Hoyer, W.D. and Maclnnis, D.J. (2010) Consumer Behavior. Peking University Press, Beijing. 
[7] Zanoli, R. and Naspetti, S. (2002) Consumer Motivations in the Purchase of Organic Food. British Food Journal, 14, 643-653. https://doi.org/10.1108/00070700210425930

[8] Williams, P. and Hammitt, J. (2001) Perceived Risks of Conventional and Organic Produce: Pesticides, Pathogens, and Natural Toxins. Risk Analysis, 21, 319-330. https://doi.org/10.1111/0272-4332.212114

[9] Ragavan, N. and Mageh, R. (2013) A Study on Consumer Purchase Intentions towards Organic Products. Paripex-Indian Journal of Research, 2, 111-114.

[10] Panyakul, V. (2012) Lao's Organic Agriculture: 2012 Update. Earth Net Foundation/Green Net.

[11] Sipaseuth, K., et al. (2008) Organic Vegetable and Fruit Production in Lao PDR. A Pre-Feasibility Study.

[12] FiBL and IFOAM. (2014) The World of Organic Agriculture. Statistics and Emerging Trends 2014

[13] Charlebois, S., McCormick, M. and Juhasz, M. (2016) Meat Consumption and Higher Prices. British Food Journal, 118, 2251-2270.

[14] Shimokawa, S. (2015) Sustainable Meat Consumption in China. Journal of Integrative Agriculture, 14, 1023-1032.

[15] Larsson, S.C. and Orsini, N. (2014) Red Meat and Processed Meat Consumption and All-Cause Mortality: A Meta-Analysis. American Journal of Epidemiology, 179, 282-289.

[16] Brščić, K., Šugar, T. and Poljuha, D. (2017) An Empirical Examination of Consumer Preferences for Honey in Croatia. Applied Economics, 49, 5877-5889. https://doi.org/10.1080/00036846.2017.1352079

[17] Henchion, M., et al. (2014) Meat Consumption: Trends and Quality Matters. Meat Science, 98, 561-568. https://doi.org/10.1016/j.meatsci.2014.06.007

[18] Ngapo, T.M. (2017) Consumer Preferences for Pork Chops in Five Canadian Provinces. Meat Science, 129, 102-110. https://doi.org/10.1016/j.meatsci.2017.02.022

[19] Krystallis, A., Petrovici, D. and Arvanitoyannis, I. (2007) From Commodities to the Consumption of Quality Foods in Eastern European Context. Journal of East-West Business, 12, 5-37.

[20] Viscusi, W.K., Huber, J. and Bell, J. (2015) The Private Rationality of Bottled Water Drinking. Contemporary Economic Policy, 33, 450-467. https://doi.org/10.1111/coep.12088

[21] O’Cass, A. (2000) An Assessment of Consumers Product, Purchase Decision, Advertising and Consumption Involvement in Fashion Clothing. Journal of Economic Psychology, 21, 545-576.

[22] Nolintha, V. and Jajri, I. (2014) The Garment Industry in Laos: Technological Capabilities, Global Production Chains and Competitiveness. Asia Pacific Business Review, 22, 110-130. https://doi.org/10.1080/13602381.2014.990209

[23] Kotler, P. (2011) Reinventing Marketing to Manage the Environmental Imperative. Journal of Marketing, 75, 132-135. https://doi.org/10.1509/jmkg.75.4.132

[24] Borland, H. and Lindgreen, A. (2013) Sustainability, Epistemology, Ecocentric Business, and Marketing Strategy: Ideology, Reality, and Vision. Journal of Business Ethics, 117, 173-187. https://doi.org/10.1007/s10551-012-1519-8

[25] Ginger and Myers (2014) Marketing Organic Vegetables. Safe Food, 23, 16-23.

[26] Pomering, A. (2017) Marketing for Sustainability: Extending the Conceptualisation 
of the Marketing Mix to Drive Value for Individuals and Society at Large. Australasian Marketing Journal, 25, 157-165. https://doi.org/10.1016/j.ausmj.2017.04.011

[27] Lin, P.-C. and Huang, Y.-H. (2012) The Influence Factors on Choice Behavior Regarding Green Products Based on the Theory of Consumption Values. Journal of Cleaner Production, 22, 11-18. https://doi.org/10.1016/j.jclepro.2011.10.002

[28] Follows, S.B. and Jobber, D. (2000) Environmentally Responsible Purchase Behaviour: A Test of a Consumer Model. European Journal of Marketing, 34, 723-746. https://doi.org/10.1108/03090560010322009

[29] Probst, L., et al. (2012) Will They Buy It? The Potential for Marketing Organic Vegetables in the Food Vending Sector to Strengthen Vegetable Safety: A Choice Experiment Study in Three West African Cities. Food Policy, 37, 296-308. https://doi.org/10.1016/j.foodpol.2012.02.014

[30] Van Hoi, P., Mol, A.P. and Oosterveer, P.J. (2009) Market Governance for Safe Food in Developing Countries: The Case of Low-Pesticide Vegetables in Vietnam. Journal of Environmental Management, 91, 380-388. https://doi.org/10.1016/j.jenvman.2009.09.008

[31] Vermeir, I. and Verbeke, W. (2008) Sustainable Food Consumption among Young Adults in Belgium: Theory of Planned Behaviour and the Role of Confidence and Values. Ecological Economics, 64, 542-553. https://doi.org/10.1016/j.ecolecon.2007.03.007

[32] Rödiger, M. and Hamm, U. (2015) How Are Organic Food Prices Affecting Consumer Behaviour? A Review. Food Quality and Preference, 43, 10-20. https://doi.org/10.1016/j.foodqual.2015.02.002

[33] Sukia., N.M., Sukib, N.M. and Azmana, N.S. (2016) Impacts of Corporate Social Responsibility on the Links between Green Marketing Awareness and Consumer Purchase Intentions. Procedia Economics and Finance, 37, 262-268. https://doi.org/10.1016/S2212-5671(16)30123-X

[34] Armstrong, G. and Kotler, P. (2009) Marketing-An Introduction. 9th Edition, Pearson International Edition, Prentice Hall, Upper Saddle River.

[35] Somervuori, O. and Ravaja, N. (2013) Purchase Behavior and Psychophysiological Responses to Different Price Levels. Psychology \& Marketing, 30, 479-489. https://doi.org/10.1002/mar.20621

[36] Zielke, S. (2011) Integrating Emotions in the Analysis of Retail Price Images. Psychology \& Marketing, 28, 330-359. https://doi.org/10.1002/mar.20355

[37] Vermeir, L. and Verbeke, W. (2005) Sustainable Food Consumption: Exploring the Consumer Attitude-Behavioral Intention Gap. Journal of Agricultural and Environmental Ethics, 19, 169-164. https://doi.org/10.1007/s10806-005-5485-3

[38] Padel, S. and Foster, C. (2005) Exploring the Gap between Attitudes and Behavior: Understanding why Consumers Buy or Do Not Buy Organic Food. British Food Journal, 107, 606-625. https://doi.org/10.1108/00070700510611002

[39] Kotler, P. and Keller, K.L. (2006) Marketing Management. Twelfth Edition, Pearson Prentice Hall, Upper Saddle River.

[40] Belz, F.-M. and Peattie, K. (2009) Sustainability Marketing. A Global Perspective. John Wiley \& Sons, West Sussex.

[41] Kim, K. (2002) Output Sector Munificence and Supplier Control in Industrial Channels of Distribution: A Contingency Approach. Journal of Business Research, 55, 427-440. https://doi.org/10.1016/S0148-2963(00)00177-6

[42] Zhu, Q. and Sarkis, J. (2016) Green Marketing and Consumerism as Social Change 
in China: Analyzing the Literature. International Journal of Production Economics, 181, 289-302. https://doi.org/10.1016/j.ijpe.2016.06.006

[43] Fahimnia, B., Sarkis, J. and Davarzani, H. (2015) Green Supply Chain Management: A Review and Bibliometric Analysis. International Journal of Production Economics, 162, 101-114. https://doi.org/10.1016/j.ijpe.2015.01.003

[44] Ajzen, I. (2011) The Theory of Planned Behaviour: Reactions and Reflections. Psychology \& Health, 26, 1113-1127. https://doi.org/10.1080/08870446.2011.613995

[45] Ajzen, I. (2001) Nature and Operation of Attitudes. Annual Review of Psychology, 52, 27-58.

[46] Ajzen, I. (2015) The Theory of Planned Behaviour Is Alive and Well, and Not Ready to Retire: A Commentary on Sniehotta, Presseau, and Araujo-Soares. Health Psychology Review, 9, 131-137. https://doi.org/10.1080/17437199.2014.883474

[47] Soonthonsmai, V. (2001) Prediction Intention and Behaviour to Purchase Environmentally Sound or Green Products among Thai Consumers: An Application of the Theory of Reasoned Action. PhD Dissertation, Nova Southeastern University, Fort Lauderdale.

[48] Singh, et al. (2017) Factors Influencing Indian Consumers' Actual Buying Behaviour towards Organic Food Products. Journal of Cleaner Production, 167, 473-483. https://doi.org/10.1016/j.jclepro.2017.08.106

[49] Chiou, J.S. (1998) The Effects of Attitude, Subjective Norm, and Perceived Behavioural Control on Consumers' Purchase Intentions: The Moderating Effects of Product Knowledge and Attention to Social Comparison Information. Proceedings of the National Science Council, 9, 298-308.

[50] Sapp, S.G. (1991) Impact of Nutritional Knowledge within an Expanded Rational Expectations Model of Beef Consumption. Journal of Nutrition Education and Behavior, 23, 214-222.

[51] Smith, S. and Paladino, A. (2010) Eating Clean and Green? Investigating Consumer Motivations towards the Purchase of Organic Food. Australasian Marketing Journal, 18, 93-104. https://doi.org/10.1016/j.ausmj.2010.01.001

[52] Liu, M.E. (2007) U.S. College Students' Organic Food Consumption Behaviour. Dissertation in Hospitality Administration, Texas Tech University.

[53] Salleh, M.M., et al. (2010) Consumer's Perception and Purchase Intention toward Organic Food Products. Exploring Attitude among Academician, 6, 119-129.

[54] Kim, H.Y. and Chung, J.E. (2011) Consumer Purchase Intention for Organic Personal Care Products. Consumer Market, 28, 40-47. https://doi.org/10.1108/07363761111101930

[55] James, B., et al. (2010) Integrated Pest Management in Vegetable Production: A Guide for Extension Workers in West Africa. IITA, Ibadan.

[56] Core, O. (2009) Certifying out of Home Operators in Europe. In: Strassner, C., Ed., CORE Organic Project Series Report 1881, International Centre for Research in Organic Food Systems, Tjele.

[57] Costa, S., Zepeda, L. and Sirieix, L. (2014) Exploring the Social Value of Organic Food: A Qualitative Study in France. International Journal of Consumer Studies, 38, 228-237. https://doi.org/10.1111/ijcs. 12100

[58] Han, H., Lee, M.J. and Hwang, J. (2016) Cruise Travelers' Environmentally Responsible Decisionmaking: An Integrative Framework of Goal-Directed Behavior and Norm Activation Process. International Hospital Management, 53, 94-105. https://doi.org/10.1016/j.ijhm.2015.12.005 
[59] Ozguven, N. (2012) Organic Foods Motivations Factors for Consumers. Procedia-Social and Behavioral Sciences, 62, 661-665.

https://doi.org/10.1016/j.sbspro.2012.09.110

[60] Chekima, B., et al. (2017) Narrowing the Gap: Factors Driving Organic Food Consumption. Journal of Cleaner Production, 166, 1438-1447.

https://doi.org/10.1016/j.jclepro.2017.08.086

[61] De Pelsmaeker, S., et al. (2017) Is Taste the Key Driver for Consumer Preference? A Conjoint Analysis Study. Food Quality and Preference, 62, 323-331. https://doi.org/10.1016/j.foodqual.2017.02.018

[62] Van Stokkom, V.L., et al. (2018) The Role of Smell, Taste, Flavour and Texture Cues in the Identification of Vegetables. Appetite, 121, 69-76.

https://doi.org/10.1016/j.appet.2017.10.039

[63] Asifa, M., et al. (2018) Determinant Factors Influencing Organic Food Purchase Intention and the Moderating Role of Awareness: A Comparative Analysis. Food Quality and Preference, 63, 144-150. https://doi.org/10.1016/j.foodqual.2017.08.006

[64] My, N.H.D., et al. (2017) Consumers' Familiarity with and Attitudes towards Food Quality Certifications for Rice and Vegetables in Vietnam. Food Control, 82, 74-82. https://doi.org/10.1016/j.foodcont.2017.06.011 